\title{
Los procesos de justicia transicional, justicia, verdad y reconciliación en el espacio Francófono y en América Latina*
}

\author{
Corina Duque Ayala" \\ Recibido: 15 de mayo de 2016 • Aprobado: 11 de junio de 2016
}

\section{Resumen}

Este artículo presenta una síntesis de la guía práctica publicada por la Organización Internacional de la Francofonía, contentiva de las experiencias en los países francófonos respecto de los procesos de justicia transicional, justicia, verdad y reconciliación. Así mismo, explica las características principales de los procesos llevados a cabo en Sudáfrica, Sierra Leona, Argentina, Chile y el Salvador, con el fin de contribuir al proceso que se lleva a cabo en Colombia con miras a consolidar una paz duradera.

Palabras clave: Justicia transicional, verdad, reconciliación, reparación, víctimas

\section{The PROCESSES OF TRANSITIONAL JUSTICE, JUSTICE, TRUTH AND RECONCILIATION IN THE FRANCOPHONE AND LATIN AMERICA CONTEXT}

\begin{abstract}
This article presents a summary of the practical guide published by the "International Organisation Francophonie, that contains experiences in francophone countries for

^ El presente artículo es resultado de la producción académica generada por el convenio suscrito entre la Universidad Santo Tomás (Sede Bogotá) y la Universidad de Bourdeux, Francia. El proyecto de investigación al que se adscribe el presente artículo es "Los retos de la Constitución y la administración frente a la paz y la seguridad ciudadana”. DOI: http://dx.doi.org/10.15332/s1900-0448.2016.0045.01

" Doctora en Derecho Público por la Universidad de Montesquieu, Burdeos 4, Francia. Docente en posgrados en la Universidad Santo Tomás, Universidad Militar Nueva Granada y la Escuela Superior de Administración Pública (ESAP), entre otras universidades y academias. Correo electrónico: corinaduque@gmail.com
\end{abstract}


transitional justice processes, justice, truth and reconciliation; It also explains the main features of the processes carried out in South Africa, Sierra Leone, Argentina, Chile and E1 Salvador, in order to contribute to the process that takes place in Colombia, with a view to consolidating a lasting peace.

Keywords: Transitional justice, truth, reconciliation, reparation, victims.

\section{Os PROCESSOS DE JUSTIÇA TRANSICIONAL, JUSTIÇA, VERDADE E RECONCILIAÇÃo NO ESPAÇO FRANCófono E NA AMÉrica LATINA}

\section{Resumo}

Este artigo apresenta uma síntese da guia prática publicada pela Organização Internacional da Francofonia, que contem as experiências dos países francófonos sobre os processos da justiça transicional, justiça, verdade e reconciliação. Também, explica as características principais dos processos acontecidos em África do Sul, Serra Leoa, Argentina, Chile e El Salvador, com objetivo de contribuir ao processo que se acontece na Colômbia com o propósito de consolidar uma paz perdurável.

Palavras-chave: Justiça transicional, verdade, reconciliação, reparação, vitima.

\section{Introducción}

Los países francófonos de África y Europa Oriental se caracterizan por la intensificación del conflicto armado en la primera década del siglo XXI, lo que ha generado rupturas en el orden constitucional y abusos en la democracia, frecuentemente acompañados de graves violaciones a los derechos humanos. Estos periodos de crisis han provocado desestabilización política y rompimiento del tejido social, razón por la cual han surgido políticas de acompañamiento a la crisis con un conjunto de dispositivos conocidos como los mecanismos de justicia transicional, justicia, verdad y reconciliación, que tienen como objetivo instaurar una paz duradera y un gobierno pacífico por medio del diálogo nacional, lo que requiere el esclarecimiento de los hechos para llegar a la verdad.

América Latina, por su lado, se caracteriza por haber sufrido durante varias décadas dictaduras militares y conflictos armados internos. Tan solo en la década de los noventa empezó a vivir una transición política con varios procesos de 
reconciliación posconflicto. Algunas naciones empezaron a buscar la estabilidad en el proceso democrático y a implementar la democratización de las instituciones.

El informe de Programa de las Naciones Unidas para el Desarrollo PNUD de 2012 señaló que América Latina asiste a una difusión de la democracia electoral, aunque con diferencias significativas en la participación que van desde un $26 \%$ en El Salvador o Guatemala hasta un 78 \% en Chile o Argentina. Desde los años noventa se viene desarrollando una reforma económica orientada a la apertura de los mercados internos, sin embargo, el PIB per cápita no aumenta, de manera que América Latina es una de las regiones más desiguales del planeta, con un $42 \%$ de la población que vive en la pobreza y un 18 \% que vive en extrema pobreza.

Argentina, Chile y El Salvador pasaron de tener gobiernos autoritarios o contextos de guerra interna a democracias aún insuficientes, y en todos ellos se vivió la ola de los procesos de transición, justicia, verdad y reconciliación, que supone romper con la tradición de las amnistías para garantizar la impunidad y buscar, por el contrario, la realización del derecho a la verdad, cumpliendo la universalidad de los derechos humanos y la globalización de la justicia. Sin embargo, el discurso sobre la reconciliación se tornó insuficiente en estos cinco países frente al número de personas que resultaron realmente afectadas y consecuentemente reparadas.

Por su lado, en Colombia, el proceso de justicia transicional empezó en 2005 con la Ley 975 conocida como la Ley de Justicia y Paz; no obstante, este primer intento ha sido fuertemente criticado por favorecer la impunidad de los paramilitares, sin que hasta la fecha se conozcan resultados satisfactorios respecto a los derechos a la verdad, la justicia y la reparación integral de las víctimas del conflicto armado interno.

Este artículo pretende analizar algunos rasgos específicos de las experiencias vividas respecto de los procesos de justicia transicional, verdad y reconciliación en los países francófonos, en Sudáfrica y en dos países latinoamericanos. En la primera parte se ofrece una síntesis de las experiencias relatadas por el profesor Fabrice Hourquebie en la guía práctica titulada Los procesos de transición, justicia, verdad y reconciliación en el espacio francófono, la cual fue publicada por la Organización Internacional de la Francofonía (en adelante OIF $^{1}$ ) como uno de los capítulos del Informe sobre el estado de las prácticas de la democracia, de los derechos y de las libertades

${ }^{1}$ Accesible en: http://www.francophonie.org/IMG/pdf/guide-oif-tjvrbat-web1003.pdf. Esta guía práctica fue traducida por la profesora Corina Duque Ayala, docente de la Universidad Santo Tomás, Facultad de Derecho en Bogotá,Maestría en Derecho Público. Correo electrónico: corinaduque@gmail.com 
en el espacio francófono en 2012. En la segunda parte de la guía se analizan las particularidades de estos procesos en Sudáfrica y en América Latina, resaltando algunas conclusiones fruto de dicha comparación, información que puede servir a los expertos colombianos con el fin de avanzar en el proceso de justicia transicional y reconciliación que se inició con la Ley 1448 de 2001, conocida como la Ley de Víctimas y Restitución de Tierras, proceso de reconciliación que el actual gobierno pretende continuar con los diálogos de paz que se adelantan en la actualidad con los miembros de las FARC en Cuba.

La metodología empleada fue la descriptiva y la analítica. Se describen y analizan las experiencias vividas en países francófonos, en Sudáfrica y Latinoamérica con relación a la justicia transicional, y se indican las actividades realizadas, los objetos, procesos y las personas. Luego se realizan los análisis del por qué y el para qué estas se habían desarrollado

\section{Los procesos de transición, justicia, verdad y reconciliación en el espacio francófono}

El profesor Chirstophe Guilhou -director para la Paz, la Democracia y los Derechos Humanos de la OIF- explica que cuando los problemas logran desestructurar y desestabilizar el Estado (guerras civiles, golpes de Estado, tomas del poder por la fuerza, etc.), el retorno de la paz es sinónimo de reconstrucción. La necesidad de justicia se vuelve entonces una necesidad para el nuevo régimen democrático, que debe mostrar su capacidad de afrontar el pasado para reconstruir una sociedad pacífica. La credibilidad del nuevo régimen implica, en primer lugar, una reconstrucción institucional del Estado que permita luchar eficazmente contra la impunidad, restaurando la capacidad jurídica de las instituciones competentes; en segundo lugar, supone la construcción de un sistema normativo confiable y estable, sin el cual toda conjetura de reconstrucción nacional está destinada al fracaso. Todo lo anterior supone la materialización de la adopción de políticas públicas con perspectiva de derechos y con amplia participación de la sociedad civil; de estamanera, los derechos humanos se convierten en el referente y fin último para las políticas públicas en materia de posconflicto (Cortez, 2016)

Por su parte, en su guía práctica de experiencias francófonas, el profesor Hourquebie (OIF, 2013) indica que la reconstrucción de la estructura estática y de las 
instituciones, así como también la restauración de la nación en el sentido de "querer volver a vivir juntos" son los objetivos principales que justifican la instauración de un proceso de justicia, verdad y reconciliación. El proyecto de reconstruir un Estado de derecho y de restaurar un gobierno pacífico después de la violencia política o de los excesos cometidos debe permitir, en un corto plazo, la refundación de una relación política sólida en el interior de una sociedad bien ordenada y organizada. Y esto ocurre porque la posibilidad de diálogo nacional y de reconciliación no es posible si no hay reconstrucción del sentimiento de pertenencia común. Sin la refundación de la memoria colectiva con el llamado a conocer la verdad de los hechos, al perdón y a la reparación no existe una verdadera posibilidad para que los individuos reencuentren una identidad común después de un periodo de violaciones masivas de los derechos humanos.

$\mathrm{Y}$ en este contexto es importante comprender muy bien cuál es el enfoque reconstructivo y reconciliador de las comisiones de la verdad y la reconciliación o de las instituciones equivalentes en los procesos en curso o por venir. Estas instituciones han sido creadas, ante todo, para revelar, comprender y establecer la historia de las violaciones pasadas con el fin de reconstruir una identidad nacional que encuentra su anclaje en el compartir de una historia común de la violencia, poniendo al día la dignidad perdida. Las historias personales se juntan para establecer una verdad y reconstruir la historia colectiva como fundamento de la refundación de ciertos consensos sociales y de la definición de un nuevo orden político y moral.

El profesor Hourquebie continúa explicando que este nuevo orden debe apoyarse en la reconciliación nacional, sin la cual las bases de la sociedad que se van a reconstruir no pueden cambiar. La reconciliación es también vista como el fin último de los procesos de justicia en el periodo de transición. Además, existen varios sentidos posibles de reconciliación, que varían de acuerdo con las historias políticas y constitucionales de los Estados y según las razones de la crisis. Así, la reconciliación puede ser reconocimiento, repetición, perdón, coexistencia pacífica, modus vivendi, restauración del sentimiento nacional, restablecimiento de un diálogo entre comunidades o entre víctimas y actores de los abusos, entre otros sentidos.

Los procesos de transición, justicia, verdad y reconciliación pueden, entonces, tener varios fines. Las hipótesis más elevadas buscan la restauración de querer vivir juntos o la reconstrucción de la armonía social anterior; por su parte, los criterios básicos buscan la regulación de la violencia, la definición de reglas de vida mínimas en una sociedad aceptable, en fin, la simple consistencia, entendida como la 
tolerancia pacífica. Uno de los problemas de estos procesos consiste, entonces, en encontrar el justo equilibrio para reconstruir ese querer vivir juntos entre un simple modus vivendi y la fabricación voluntarista, entendida como artificial-, de una unidad política reforzada.

De suerte que aparecen dos preguntas centrales: ¿se puede lograr siempre un consenso nacional pleno y total sobre la interpretación de un pasado doloroso? ¿Es necesario para la paz y la reconstrucción de una sociedad que cada individuo comparta una perspectiva única sobre los hechos? (Andrieu, 2012). El reto de estos procesos de transición, justicia, verdad y reconciliación es siempre conciliar, dentro de una sociedad dividida y en un contexto postraumático de conflicto armado, la búsqueda de una paz durable y de la lucha contra la impunidad, en la cual todas las partes, todas las comunidades puedan reconocerse para no olvidar el pasado opresor y a partir de esta verdad colectiva seguir juntas hacia el futuro que se debe construir.

Es así como Hourquebie aclara que la justicia transicional es diferente de la justicia institucional. La instauración de mecanismos de transición, justicia, verdad y reconciliación no es exclusiva de la actividad de investigación de las instituciones judiciales cuando estas últimas aún están funcionando. Solo hace falta que los procedimientos de la justicia institucional, formal, que buscan regular las relaciones sociales entre individuos y el poder en una sociedad estabilizada entreguen una justicia basada en la naturaleza de la sanción, pudiendo no funcionar más. El aparato jurisdiccional que se encuentra operando está confrontado a sus límites estructurales porque se han cometido abusos tan masivos de una parte en contra de la otra, que la justicia clásica resulta ineficaz; porque los otros, es decir, los abusadores, están aún en el poder e impiden, por ello mismo, que la justicia funcione; $y$ finalmente porque en la justicia formal, que funciona sobre la base de la prueba -es decir, una acusación es formulada, y le corresponde a la sociedad aportar los fundamentos de esta acusación-,en ciertos periodos de la historia, la distinción entre víctimas-victimarios puede ser tan difícil que la idea misma de la prueba no puede funcionar u operar.

En consecuencia, puede parecer necesario suplir esta justicia formal, retributiva, que en una situación de crisis no funciona, por una justicia transicional, restaurativa y reconstructiva. En efecto, si la justicia penal, formal, puede funcionar normalmente en periodo de posconflicto, ella está muy lejos de cumplir su función en periodo de transición, en razón del carácter a la vez derogatorio y excepcional de la situación a la cual se encuentra confrontada. El recurrir a otras formas de justicia más 
innovadoras en todo caso sobrepasa la simple concepción orgánica y procedimental de la justicia formal, lo que debe permitir aportar unas respuestas más adaptadas en una perspectiva de la lucha contra la impunidad y la refundación del tejido social. La justicia se vuelve, entonces, una exigencia en nombre de la pacificación social más que una institución para movilizarse al servicio de un arbitraje jurídico.

Esto ocurre porque la justicia es, en efecto, un concepto vasto que puede tomar una significación particular en el contexto de un proceso de salida de crisis. Ella es, ante todo, una necesidad: de reconocimiento de la dignidad de la persona o de un grupo; de reparación material para reconstruirse; de punición y de sanción. Ella puede pasar por retomar el diálogo entre los protagonistas del conflicto o apoyarse en el juzgamiento, la sanción y, por tanto, en la identificación clara de los actores de los crímenes, de las víctimas, de los hechos judiciales establecidos, de las normas por aplicar. Ella es reconstructiva y punitiva; restaurativa y sancionadora; ella es un todo que sobrepasa la sola sanción, pero que no la excluye. Además de esta enseñanza, es posible preguntarse si se puede verdaderamente hablar de justicia a lo largo de los periodos de transición en la medida en que los dispositivos movilizados no surgen expresamente de la justicia, sino que son unos instrumentos más o menos formalizados de ingeniería transicional lato sensu, instrumentos movilizados precisamente para restaurar el funcionamiento de la justicia formal y, más ampliamente, para disminuir las tensiones a lo largo de la crisis o al salir de esta.

Los procesos de justicia transicional, verdad y reconciliación van siempre más allá de los límites impuestos por el derecho a la justicia clásica. Los fundamentos de esta justicia en periodo de transición no pueden estar aprisionados en la coraza normativa y procedimental de la justicia institucional, y deben responder a un objetivo que supera a la sola sanción, representando, de todos modos, avances determinantes en el proceso de lucha contra la impunidad por las violaciones graves de los derechos humanos, la reconstrucción del tejido nacional y la restauración, in fine, del Estado de derecho.

Respecto de las relaciones de esta justicia con la Constitución de cada país, el profesor Hourquebie explica que cada proceso de reconstrucción supone la movilización de una variedad de dispositivos adaptados a la diversidad de las culturas jurídicas y, más ampliamente, a pluralismos de la nueva sociedad que progresivamente permiten la emergencia de un nuevo Estado de derecho.

La justicia en periodo de transición debe tener en cuenta la Constitución como fundamento del Estado de derecho. Así, el proceso de transición, justicia, verdad 
y reconciliación es objeto de negociaciones durante el proceso preconstituyente que tiende a definir las opciones fundamentales de la nueva Constitución. En ese contexto, la justicia en periodo de transición se vuelve un capítulo clave del cuaderno constitucional de obligaciones. Su consagración en la carta magna no implica su permanencia -so pena de controvertir el carácter transitorio del dispositivo-, por el contrario, sí marca la toma de conciencia de los constituyentes respecto de la prioridad de dar a estos dispositivos el carácter de solución específica de transición.

De otra parte, los estándares sobre la base en que deben funcionar esos dispositivos han de estar conformes no solamente con el derecho internacional, sino también, y sobre todo, con las prescripciones y el contenido de la nueva Constitución. Varias hipótesis de una justicia en periodo de transición se presentan:

- Una acompañada de una salida de la crisis caracterizada por un cambio constitucional con la adopción de una constitución definitiva.

- La relacionada con la adopción de una Constitución de transición ("pequeña Constitución”, "Constitución interina”, “Constitución intermediaria”).

- Otra que resulta del mantenimiento de la antigua Constitución en el caso de una ausencia de transición constitucional.

En todo caso, los principios directores de la justicia de transición no pueden prescindir del respeto de los derechos fundamentales, ya que el carácter derogatorio de los procesos no justifica todas las exclusiones; mucho menos se puede sustraer de los controles eventualmente previstos por la Constitución (por la vía de las cortes constitucionales, la Corte Suprema, la vía del procedimiento parlamentario de elaboración de leyes, etc.) tanto en la forma como en el proceso y en el fondo.

En cuanto a los principios rectores que deben regir en una justicia transicional, aunque eminentemente relativos a los países en donde estos han sido desplegados, los procesos de justicia, verdad y reconciliación se ordenan alrededor de cuatro fundamentos puestos en evidencia por Luis Joint en su informe sobre la lucha contra la impunidad, presentado a la Comisión de Derechos del Hombre en 1997 (Joinet, 2007). El enfoque de la francofonía se funda muy lógicamente sobre esos principios en la medida en que, de una parte, se articulan con los estándares del derecho internacional público, coincidiendo así con las obligaciones generales que este último exige a los Estados cuando sobrevienen violaciones graves a los derechos humanos y cuando, de otra parte, ellos son una autoridad adscrita a la comunidad internacional. 
- Así, los Estados están obligados a:

- investigar sobre las violaciones graves a los derechos del hombre;

- tomar medidas adecuadas con respecto a los autores de esas violaciones;

- asegurar a las víctimas de las vías de recurso eficaces, velando velando así por que ellas reciban reparación del perjuicio recibido, y

- garantizar el derecho inalienable de conocer la verdad sobre esas violaciones y tomar las medidas destinadas para evitar que tales violaciones no se reproduzcan.

A cada una de esas obligaciones -que incumben al Estado- corresponde un derecho -en beneficio de las víctimas-, en el cual el fin último del proceso de transición, justicia, verdad y reconciliación consiste en determinar el grado de oposición $\mathrm{y}$, por tanto, de efectividad.

El profesor Hourquebie explica, en primer lugar, el derecho a la justicia, indicando que la justicia en periodo de transición no debe excluir el derecho al juez; por el contrario, debe garantizar la efectividad de ese derecho (cf. Artículo 14 del Pacto Internacional, relativo a los derechos civiles y políticos). Por lo tanto, es necesario que desde el principio de la transición sea dada una prioridad a la reforma de la justicia y su administración, con el fin de que la justicia ordinaria tome su ritmo de trabajo y que desde allí sea posible "llegar" a la justicia de transición una vez las tensiones se hayan calmado o el proceso de la salida de la crisis se haya consolidado. La escogencia de la jurisdicción competente es, pues, importante; puede tratarse de una jurisdicción nacional, de una jurisdicción híbrida, -como las cámaras extraordinarias en el interior de los tribunales de Camboya o el Tribunal especial del Líbano, o aún de un tribunal ad hoc, como el Tribunal Penal Internacional para Ruanda-, o avanzando hacia una justicia permanente, como la Corte Penal Internacional. Más ampliamente, el recurrir a los procesos extrajudiciales puede ser visto, en un todo y siempre, en una lógica de complementariedad y de articulación con los mecanismos jurisdiccionales. Cada una de estas formas, que presenta puntos fuertes y débiles, debe fijar las reglas en materia de competencia temporal y material, de sanción, de amnistía y de reparación.

Del derecho a la justicia se desprende el derecho a la verdad. Las investigaciones son frecuentemente organizadas en el contexto de instituciones que pertenecen a la familia de las comisiones de la verdad (y la reconciliación). Estas comisiones tienen por misión "recoger las informaciones que permitan la mejor comprensión de los mecanismos de opresión violadores, con el fin de evitar su repetición” (Joinet, 2007). 
El derecho a la verdad toma la forma de un deber de memoria (que permite traer la luz y el conocimiento para un pueblo, de su opresión), pero también de un derecho a saber, en beneficio de las víctimas (conocer la verdad sobre las circunstancias en las cuales las violaciones de los derechos del hombre han sido cometidas).

Los mecanismos de esclarecimiento de los hechos son plurales y se encuentran principalmente en el espacio francófono de comisiones de investigación y de comisiones de la verdad. Estas últimas permiten dirigirse a miles de víctimas con el fin de comprender la amplitud y los tipos de violaciones cometidas y establecer su realidad. Las comisiones de la verdad no están destinadas a ser tratadas como tribunales, y no pueden ser un substitutas de un proceso judicial tendiente a establecer las responsabilidades criminales individuales. Ellas retoman las conclusiones al final de sus pesquisas, conclusiones sobre la base de que ellas devuelven a las jurisdicciones nacionales la obligación de comprometerse o no con las investigaciones. Allí, aun, la articulación con las jurisdicciones debe jugar un papel importante. Reaparece el principio de complementariedad evidenciado en forma precedente, presente en el funcionamiento de los procesos de transición, justicia, verdad y reconciliación.

En un tercer momento, el derecho a la reparación se materializa en el reconocimiento del perjuicio establecido. La reparación del perjuicio puede tomar varias formas. Puede, en efecto, tratarse de una indemnización material, de una restitución de bienes, de medidas de rehabilitación para las víctimas, de medidas simbólicas, por ejemplo, las excusas públicas, una conmemoración o una memoria. Toda recomendación tendiente a la reparación no debe ser considerada como un substituta de la traducción de responsables en justicia ni como un obstáculo para las víctimas de demandar también la reparación ante los tribunales (y, por tanto, de obtener una sanción jurídica).

Finalmente, deben ser propuestas unas garantías de no repetición y de reformas institucionales. El Estado debe proceder a la verificación (verificación y filtraje institucional) y a la creación de reformas, especialmente en materia de sistemas de seguridad (RSS) y de justicia -esto con el fin de permitir la responsabilidad penal con respecto a las violaciones del pasado y a asegurar que las instituciones políticas eficaces y equitativas puedan prevenir los eventuales abusos en el futuro-, verbigracia, el desarme, la desmovilización y la reinserción (DRR), cuestiones de las violaciones masivas de los derechos humanos que son tan frecuentemente cometidas por los agentes de seguridad. 
Ello ha se der así porque la justicia de transición tiene una función más restauradora que la misma justicia ordinaria, pues esta última tiene una limitación en los medios y en la amplitud en los abusos cometidos, lo que la hace incapaz de administrar justicia de manera eficiente, razón por la cual sus principios no pueden ser tomados en una concepción estricta, por el contrario, deben ser entendidos lato sensu como aquellos cuya finalidad es el despliegue de todo su poder al servicio de la reconstrucción, la restauración de lazos nacionales y, finalmente, de la reconciliación.

Así, el derecho a saber más allá de la simple cuestión de la prueba; el derecho a la justicia que se emancipa de las reglas clásicas del derecho penal e interroga directamente por la amnistía y las demás medidas de clemencia, desplegando diversas vías de investigaciones judiciales; el derecho a la reparación que la busca subsidiariamente en el plan pecuniario, pero pretende, además, un derecho a la restitución, a la compensación, a la satisfacción; y la garantía de no repetición, todos se entienden como el derecho de comprometerse con profundas reformas institucionales -más allá de la sola verificación que hace el aparato judicial- y a adoptar medidas con el fin de permitir el respeto del Estado de derecho, interiorizar una cultura de derechos humanos y restablecer la confianza de la población en sus instituciones.

En consideración a los elementos precedentes, la guía de experiencias en países francófonos que nos presenta el profesor Hourquebie no tuvo como finalidad la imposición de un modelo de referencia ni privilegiar una solución más que otra para alcanzar la reconciliación, tampoco hallar un "modo de empleo" o unas claves. Por el contrario, la idea de la guía consistió en consignar las diferentes prácticas en materia de procesos de transición, justicia, verdad y reconciliación que permitieran subrayar la legitimidad y la variedad de experiencias en curso, además, con la diversidad de los derechos en el Estado y la manera como el diálogo de los derechos y de las culturas puede contribuir al apaciguamiento de un conflicto. E1 surgimiento de la verdad, el deber de hacer memoria, el derecho a la justicia, la lucha contra la impunidad por la represión de los crímenes y los abusos son, para este académico, objetivos indisociables a corto y a mediano plazo, y deben estar al servicio de la reconciliación y la restauración del sentimiento nacional, elementos necesarios para lograr la reconstrucción de un Estado de derecho y el mantenimiento de una paz durable. 
Ahondando en esta diversidad de experiencias, el profesor Hourquebie explica que las normas y los mecanismos de justicia, verdad y reconciliación en periodo de transición no pueden ser absolutamente uniformes ni monolíticas; por el contrario, deben ser suficientemente flexibles para adaptarse a la diversidad y a la complejidad de las situaciones y circunstancias en las cuales se despliegan. La constatación actual es aquella de una extensión del espectro de la justicia en periodo de transición más allá de lo que constituye la característica primera del Estado de la construcción del concepto, a saber, la transición política y constitucional.

En realidad, la mayoría de los procesos de justicia, verdad y reconciliación en el espacio francófono se han instaurado en un contexto de crisis, sin que por ello sean alternativas política al poder, entendidas como transición constitucional. Dicho de otro modo, la mayoría de los procesos de justicia en periodo de transición se establecen más allá de todo cambio institucional y constitucional, lo que tiene por consecuencia la limitación de la efectividad de las medidas de justicia en periodo de transición, de una parte, y el debilitamiento del trabajo de la institución, de otra parte, relativizando el alcance de recomendaciones producidas en su informe final del poder en ejercicio pudiendo caucionar (entiéndase ordenar) las violaciones de los derechos humanos que han justificado precisamente la instauración de un proceso de justicia, verdad y reconciliación.

En toda hipótesis, la reconciliación no puede ser la sola clave de identificación, pues ella es directa o indirectamente, de manera explícita o implícita, el objetivo general de cada mecanismo.

Para identificar bien el tipo de institución movilizada, lo importante es, entonces, encontrar el hecho generador que ha conducido a la instauración de un proceso de transición de justicia, verdad y reconciliación, y particularmente a la implementación de una comisión de la verdad o de una institución equivalente.

La observación de las experiencias en el espacio francófono conduce a formular una constante al final que consiste en que dos situaciones principales inducen un proceso de justicia en periodo de transición.

La constante que se encuentra ciertamente en la cumbre de algunas ideas recibidas sobre estos procesos es, efectivamente, aquella según la cual la dimensión "transición constitucional", que con frecuencia se utiliza para recurrir a los mecanismos de justicia en periodo de transición, no logra en realidad, sino muy raras veces, implementar esos dispositivos. La transición no es determinante, entonces, en las mutaciones constitucionales, que son tan escasas. Dicho de otro modo, la mayoría 
de las situaciones en el espacio francófono son hipótesis en las que los procesos de transición, justicia, verdad y reconciliación implementados no conducen a una transición institucional efectiva ni tampoco se basan previamente en un objetivo de transición institucional.

Las dos situaciones privilegiadas que conducen a la instauración de procesos de justicia, verdad y reconciliación en el espacio francófono son, de una parte, las hipótesis de crisis o de salida de la crisis, y, de otra parte, las hipótesis de memoria.

En periodo de crisis o de salida de crisis, los mecanismos de justicia, verdad y reconciliación son los instrumentos de un retorno a la calma y poseen las bases de la pacificación. De esta forma, el enfoque, no es solamente función de las circunstancias sino también del momento en el que se decida instaurar el dispositivo de justicia, verdad y reconciliación. La temporalidad en el recurso al instrumento es estratégica: ella condiciona la secuencia del proceso y su éxito (en términos de pacificación de las partes, luego de una consolidación de la reconciliación) o su fracaso (confusión de procedimientos judiciales y no judiciales; incapacidad de la comisión de la verdad o de investigación de actuar en razón de las fuertes presiones de las partes políticas y fuerzas armadas especialmente; clima de inestabilidad crónico, etc.). Así, durante la crisis, el anuncio de la movilización de los procesos de justicia, verdad y reconciliación debe contribuir en la urgencia a un retorno a la calma, a apaciguar las tensiones y a hacer caer la intensidad de la crisis. A la salida de la crisis, es decir, cuando la situación es menos estremecedora, estos procesos se vuelven además instrumentos de diálogo nacional y de reconciliación, y tienden a la construcción de un diálogo estructurado y más estructural, es decir, en el mediano plazo, destinado a contribuir a la reconstrucción de las bases sólidas del nuevo Estado y de la comunidad nacional, que debe ser su encarnación.

Más particularmente en periodo de crisis o de salida de la crisis, se trata de situar bien el momento de recurrir al proceso de justicia, verdad y reconciliación en el proceso de paz. Es cierta especialmente la especificidad de la situación del terreno (naturaleza del conflicto, tipología de la crisis, hechos generadores de la crisis, etc.) y el contexto global (historia, actores, trayectoria constitucional, grado de consenso en la sociedad concernida, peso de la sociedad civil, etc.) que debe condicionar:

1. la naturaleza de los procesos de justicia, verdad y reconciliación que se van a implementar;

2. el momento de su integración en el desarrollo de la crisis o en la poscrisis; 
3. la secuencia de las diferentes acciones que se van a implementar con respecto a los cuatro pilares tradicionalmente identificados (derecho a la verdad, derecho a la justicia, derecho a la reparación y garantías constitucionales de no repetición de violaciones de derechos humanos), lo que es:

a) temporal ante todo (y en dos niveles de lectura) en una aprensión holística de los procesos en cuanto a instaurar el dispositivo institucional de justicia, verdad y reconciliación; también temporal en una apreciación casuística de trabajo de la comisión sobre un periodo de funcionamiento que debe permitirle alcanzar sus objetivos (temas como la duración del mandato). Y surge la pregunta: ¿cuál es el periodo de la apertura para el trabajo de la comisión (tema del periodo del mandato)?

b) Material: ¿qué tipos de violaciones deben ser sometidas a investigación?

En los procesos de memoria, la temporalidad bien entendida es importante, pero la cuestión de la secuencia no se hace evidente porque las comisiones no intervienen "en calor", sino más bien después de que ha pasado cierto tiempo, propiciando la pacificación y no el olvido, para que la situación trágica que ha marcado la historia de un pueblo se vaya desvaneciendo después. Así, el trabajo de una comisión de la verdad en una perspectiva de memoria es aquel que establece los hechos con la distancia suficiente que dará al trabajo de investigación toda su legitimidad en aras de esclarecer una parte de la historia y de restablecer el sentimiento nacional, el sentimiento de pertenencia a los fines que se comparten, de la manera más pacífica posible, en una historia que, siendo común, no es compartida, y que ha dividido profundamente a la sociedad.

De un lado está la crisis o la salida de la crisis de un lado (consecuencia de las violencias políticas y/o de las violaciones de los derechos humanos), y del otro lado está la memoria del otro. Es alrededor de estas dos situaciones que se han clasificado los dieciséis países del espacio francófono que han recurrido o recurren actualmente a estos procesos (cifra que pasa a veinte si se contabilizan los países que piensan implementar estos dispositivos). El conjunto de instrumentos movilizados (comisión de la verdad, comisión de investigación, tribunales especiales, jurisdicciones internacionales, justicia tradicional, etc.) para implementar estos procesos cubre veintiséis experiencias institucionales, tipos de procesos de transición, justicia, verdad y reconciliación. 
A título de comparación, tres situaciones emblemáticas -ya sea por el éxito, ya sea por el carácter extremadamente marcado sobre el plano histórico- han sido escogidas para ser puestas en relación con las experiencias francófonas:

1. África del Sur, por su anterioridad y el modelo que ella puede representar, especialmente en el plano de su funcionamiento; sobre aquella, transaccional, del otorgamiento de amnistía contra testimonios y porque se trata de una de las raras experiencias de justicia en periodo de transición en situación de transición constitucional.

2. La Sierra Leona, Estado anglófono en un espacio del oeste africano en su mayoría francófono, regularmente citado en referencia por los actores de los procesos más recientes de justicia, verdad y reconciliación, especialmente porque la composición de la comisión de la verdad fue establecida sobre un modelo similar al de la experiencia sudafricana y porque la Sierra Leona es característica de una justicia en periodo de transición que reposa sobre la coexistencia entre un mecanismo no judicial (la Comisión de la Verdad y Reconciliación) y un mecanismo jurisdiccional (E1 Tribunal Especial para la Sierra Leona).

3. Chile, ejemplo característico de mecanismos de justicia, verdad y reconciliación sobre el subcontinente suramericano, tierra que ha visto nacer y multiplicarse estos procesos, que, de manera única, ha visto suceder una comisión de la verdad y una comisión de investigación, y cuya experiencia sobre el plan de seguimiento e implementación de recomendaciones es destacable.

El crecimiento de estas experiencias puede conducir a interrogarse sobre los factores que guían la escogencia de mecanismos de justicia, verdad y reconciliación (lógica regional, sistema de derecho; naturaleza y transformación del conflicto; naturaleza de crímenes objeto de investigación, grado de estructuración de la sociedad civil; fuentes tradicionales, etc.) y acerca de la naturaleza de los dispositivos movilizados.

Se pregunta el profesor Hourquebie ¿cuáles serían las principales etapas en la implementación de los dispositivos? Y responde lo siguiente:

Todas las situaciones que conducen a la instauración de los dispositivos de justicia, verdad y reconciliación son diferentes; conviene entonces que cada institución encargada de tal dispositivo se dedique a construir sus estrategias específicas y adaptadas a los contextos. No es menos cierto que las constantes técnicas organizacionales pueden ser experimentadas. A título de ejemplo, he aquí algunas 
prácticas indispensables para un cronograma tipo deseado, para adaptarse según la amplitud del mandato:

- Elaborar un reglamento interno.

- Llevar a cabo rápidamente una campaña de movilización de los fondos adscritos a las partes bilaterales y multinacionales, porque la contribución de las partes llega siempre muy tarde: elaborar un documento de presentación, como un plan de acción (actividades interrumpidas, cronograma de actividades, misiones...) con la ayuda de los socios internacionales que pueden facilitar, por su presencia, la identificación y determinación de los puntos clave que se esperan, para poder establecer así un presupuesto provisional destinado al financiamiento del proceso (un presupuesto mediano para el trabajo de tres años puede ser evaluado en 5 millones de dólares, pero este presupuesto será seguramente sobrepasado.

- Establecer una estrategia de comunicación:

$\checkmark \quad$ Sensibilizar a las partes políticas y a la sociedad civil para escoger en equipo desde la comisión.

$\diamond \quad$ Construir un sitio web o como mínimo una página Internet que puede ser actualizado/a regularmente con las actividades de la comisión o sus miembros.

$\diamond \quad$ Acreditar a los periodistas adscritos a la comisión con el fin de que ellos comprendan perfectamente su trabajo y que lo restituyan fielment

$\diamond \quad$ Construir un plan de medios de comunicación al servicio de la instalación de la comisión para presentarla; después, prever las intervenciones regulares para hacer un balance de avance de los trabajos; y finalmente, un plan de medios al servicio del envío del informe y las conclusion

$\diamond \quad$ Prever que solo el Presidente de la comisión tome la palabra en nombre de la comisión (entrevistas, declaraciones, etc.) con el fin de evitar toda distorsión y garantizar así la claridad y la coherencia de la comunicación.

- Sensibilizar los comisionados al mandato:

$\diamond \quad$ Apropiación del sentido y la envergadura de su mandato.

$\diamond \quad$ Hacer aceptar el mandato por las partes que se van a reconciliar.

$\diamond \quad$ Interpretar el mandato de manera constructiva en el sentido favorable a la reconciliación.

- Identificar los momentos claves del periodo que se va a investigar:

$\diamond \quad$ Operar con lo escogido. 
$\diamond \quad$ Hacer resúmenes para no ser sorprendido por el flujo de los acontecimientos.

$\diamond \quad$ Poseer criterios para retener los hechos significativos.

$\diamond \quad$ Resignificar los hechos en el contexto global de la historia nacional.

$\diamond \quad$ Hacer una hipótesis inicial de la historia.

- Crear subcomisiones con un personal dedicado (subcomisiones para las declaraciones; subcomisiones para las investigaciones; subcomisiones para las finanzas, etc.).

- Visualizar la posibilidad de recurrir a expertos externos.

- Formar a los delegados susceptibles de ir a recoger los testimonios sobre todo el territorio (periodistas de investigación, personas de la sociedad civil).

- Adoptar el principio y las modalidades de las denuncias, y constituir una base de datos de estas últimas y de los testimonios recogidos multiplicando las claves de entrada (identidad de la víctima, naturaleza de la violación, sexo, edad, lugar, fecha, etc.).

- Pasar a las audiciones, lo que implica:

$\diamond \quad$ identificar el procedimiento que se va a desarrollar en las audiciones (plenaria, formaciones restringidas, tipo de preguntas hechas, etc.),

$\diamond \quad$ seleccionar los casos que se van a escuchar y

$\checkmark \quad$ escoger la forma de audición (pública, a puerta cerrada, privada, etc).

- Prever las audiencias foráneas que permiten a la comisión desplazarse hasta las poblaciones.

- Adoptar un informe final (y la necesidad de informes intermediarios a fechas fijas durante el mandato) y velar por su publicación efectiva.

- Prever una rúbrica en los informes que enlistan las recomendaciones.

- Proponer una instancia de seguimiento para evaluar la implementación de las recomendaciones:

$\diamond$ Seguimiento por una institución existente, tipo Comisión Nacional de Derechos Humanos.

$\checkmark \quad$ Seguimiento por una institución ad hoc.

En conclusión, en cada país francófono los procesos han sido variados, ya que no hay una experiencia como modelo único adaptable a cada uno, pero sí hay un acumulado de experiencias, de aprendizajes que sirven como ejemplo o referencia para fortalecer los movimientos de víctimas en su empeño de superación de la impunidad y exigencia de sus derechos. 
Se describen a continuación algunos detalles del proceso de reconciliación que se vivió en Sudáfrica y se compara con los procesos de dos países latinoamericanos.

\section{El proceso de reconciliación en Sudáfrica y una comparación con los procesos de Argentina, Chile y El Salvador}

Respecto del proceso en Sudáfrica, la profesora Ethel Nathaly Castellanos, en el artículo "Verdad, justicia y reparación en Argentina, Salvador y Sudáfrica", publicado en la revista Socio-Jurídica, hace un análisis interesante de los resultados de cada proceso, enfatizando en los avances alcanzados en Sudáfrica y en los tres países comparados de Latinoamérica. Entre las conclusiones más importantes se encuentran las siguientes:

- La investigación académica comparada permitió constatar que Argentina, El Salvador y Sudáfrica han vivido regímenes dictatoriales, lo que produjo un impacto nacional e internacional de sus conflictos y una trascendencia de sus procesos de justicia transicional. Argentina fue la dictadura en el Cono Sur con más avances en el derecho a la justicia. El Salvador enfrentó un proceso de paz luego de un conflicto armado interno prolongado y crudo, con algunas similitudes del conflicto colombiano.

- La experiencia de Sudáfrica muestra que un conflicto totalmente diferente de los demás, brutal y prolongado puede llegar a tener salida; incluso Sudáfrica sigue siendo hoy el mejor ejemplo en cuanto al diseño de un proceso de paz y reconciliación de los que hasta ahora conocemos.

- Todos estos países tuvieron una etapa previa a la firma de los acuerdos de paz o al retorno del gobierno civil. También tuvieron una segunda etapa llamada nuclear, conocida como el periodo comprendido entre el acuerdo de paz y el límite establecido para llevar a cabo la transición, tiempo permitido para la labor de las comisiones de la verdad o para acudir al aparato judicial. Por último, tuvieron una etapa posterior, que se cuenta desde el límite mencionado hasta la actualidad.

- Las experiencias estudiadas demuestran la importancia de no excluir a los militares de la reconciliación a pesar de la existencia del castigo; contar 
con ellos es la mejor forma de esclarecer la verdad, hacer justicia y lograr la reconciliación.

- Se evidencia, además, la importancia de garantizar la independencia de las ramas del poder público y de fortalecer la vigilancia de los ciudadanos. A estos se les debe garantizar la posibilidad de acceder a las Comisiones de la verdad (los fracasos de ciertos movimientos sociales no fueron en realidad fracasos, por cuanto provocaron que se retomaran los temas que se requería clausurar, lo que constituye un triunfo no despreciable para los movimientos de las víctimas).

- Las audiencias públicas en Sudáfrica contribuyeron a la reconciliación, por cuanto se dio a conocer a la opinión pública el estado del proceso y se pudo reconstruir la historia, punto al que infortunadamente aún no logrado llegar Argentina. Estas audiencias contribuyeron, además, a construir en el imaginario la figura de una sociedad unida, que trabaja por una obligación común de encontrar la verdad.

- El proceso sudafricano es el que más se acerca al reconocimiento del derecho a la justicia. Se evita hablar de la derrota del oponente. Se reconocen los intereses recíprocos. Este contribuye a la generación de un ambiente propicio para plantear soluciones.

- En Argentina, por el contrario, los militares siempre fueron conscientes de su dominio y de su poder, lo que generó confesiones fingidas y tardías, reconciliaciones fingidas; f ue solo después de doce años que las confesiones empezaron.

- Sudáfrica es ejemplo de los límites que deben imponerse ante una posible politización radical de la justicia.

- Como fracasos podemos hablar del proceso de reinserción en términos de criminalidad común, lo cual ocurrió en El Salvador y en Sudáfrica. Por lo tanto, para evitar nuevas bandas de delincuentes, se deben adoptar medidas para eliminar la pobreza, porque aún se observan marcadas diferencias económicas en el interior de estos países e incumplimiento de los acuerdos con los reinsertados.

- Como logros se recalca el gran entendimiento de la sociedad sobre el derecho y la justicia. La Comisión de la Verdad tuvo, a su vez, tres comités que realizaron la verdad, la justicia y la reparación: el Comité de Rehabilitación, el Comité de Amnistía y el Comité de Reparación. 
- Se concluye que cuando una sociedad se compromete con la construcción de un nuevo orden político, el Estado empieza a responder por sus errores

- Finalmente, se recalca nuevamente que los movimientos de víctimas cumplen una función esencial, ya que actúan como grupos de presión, ayudan a mantener la memoria viva, informan a la opinión pública, ofrecen apoyo legal y contribuyen a rescatar la dignidad y la confianza personal. Es decir, las víctimas son actores sociales y políticos de los diferentes procesos de democratización que se han llevado a cabo en Latinoamérica. Sin embargo, son muchas las dificultades y los retos que han tenido que afrontar y sufrir, desde la revictimización, la estigmatización social o la persecución por la exigencia de sus derechos en sus esfuerzos por mantener viva su memoria y dignidad. Estos movimientos de víctimas han encontrado un espacio fructífero en las comisiones de la verdad y la reconciliación que se han creado en el interior de cada país.

Respecto de las comisiones de la verdad en América Latina, se tiene que, al igual que lo que ocurre en los países francófonos, estas iniciativas no son cuerpos judiciales ni deben considerarse como sustitutos de los juicios penales. Son entidades temporales que investigan patrones de abusos y violaciones de derechos humanos y normas humanitarias cometidos en un periodo determinado. Están oficialmente facultadas por el Estado, y en algunos casos, por la oposición o por un acuerdo de paz respaldado por las Naciones Unidas (IIDH, 2006a).

El esclarecimiento de los hechos y, por ende, la búsqueda de la verdad, son elementos indispensables para avanzar en los procesos de reconciliación. En América Latina, específicamente en los casos de Argentina, Chile, El Salvador, Guatemala y Perú, las comisiones de la verdad han sido un paso fundamental para dar respuesta a la deuda pendiente con las víctimas de la violencia y con la sociedad en su conjunto; también han servido para superar, en muchos casos, la negación sistemática de los hechos históricos y para evitar la complicidad de las instituciones del Estado con estos crímenes, a las cuales la víctima debía recurrir para denunciar las violaciones.

Entre los aportes de las comisiones de la verdad en sociedades en transición, se pueden destacar los siguientes:

- “(...) Ayudan a establecer la verdad sobre el pasado.

- Promueven que los perpetradores de las violaciones a los DDHH asuman su responsabilidad. 
- Brindan una plataforma pública a las víctimas.

- Informan y catalizan el debate público.

- Recomiendan reparaciones para las víctimas.

- Recomiendan las reformas legales e institucionales necesarias.

- Promueven la reconciliación.

- Ayudan a consolidar una transición democrática.

A pesar de su potencial, su conformación también despierta reacciones diferentes, porque hay sectores que manifiestan nuevamente el temor a que se recrudezca la violencia si se llegan a investigar los crímenes del pasado. La clase dirigente puede mostrar, en algunos casos, poco interés en la investigación; puede haber presiones hacia leyes de amnistía, más que hacia el conocimiento de la verdad. Y, a pesar del acuerdo parlamentario, en su conformación es posible que tengan que enfrentar obstáculos financieros y políticos. Por otro lado, constituyen una esperanza para amplios sectores de la sociedad civil, en particular asociaciones de víctimas, grupos de derechos humanos y líderes religiosos e intelectuales que impulsan el establecimiento de la comisión, y son una garantía para el proceso. (IIDH 2006b).

Se anota que cuando una comisión de la verdad entrega su informe final, archiva sus expedientes y se disuelve formalmente; el cumplimento de sus recomendaciones recaen, generalmente, en el poder ejecutivo y en parte del Gobierno. Con frecuencia se constata que existe una falta de voluntad política para cumplir las recomendaciones hechas por la Comisión y siempre ha habido problemas de fondos insuficientes.

En el interior de las comisiones de la verdad y la reconciliación, por tratarse de un mandato restringido, por parte de las víctimas se siente mucho escepticismo respecto a sus resultados, pero esto no significa que se desconozcan sus aportes a los procesos de paz y reconciliación. Estas comisiones proponen mecanismos adecuados de monitoreo y seguimiento que incluyen algunas acciones. El gran riesgo es la frustración que llegan a sentir las víctimas cuando constatan la falta de voluntad política para reparar estos hechos.

De otra parte, se anota que las políticas de la memoria o el derecho a la verdad no son lineales en ningún país latinoamericano, al igual que ocurrido en los países francófonos. Ellas están sometidas a contradicciones sociales, equilibrios de poder y a la posibilidad que tienen los diferentes actores sociales y políticos de colocar el tema en la agenda pública. El trabajo de las comisiones de la verdad es un punto 
de partida, pero las respuestas tardías del gobierno son indicadores de la falta de voluntad para asumir dicha responsabilidad.

Por último, se recalca que las experiencias en Latinoamérica en cuanto a las comisiones de la verdad han demostrado que es fundamental que en la conformación de estas se asegure una amplia legitimidad moral y un equilibrio justo entre la representación de tendencias políticas, grupos religiosos, étnicos y grupos vulnerables en general.

Aunque cada proceso sea diferente dentro de cada país, las comisiones de la verdad en América Latina son espejos en los que puede mirarse la experiencia de los otros como iguales: pueden ayudar a tomar conciencia de las similitudes y diferencias, también de los factores de crisis, fracasos y experiencias positivas o negativas.

A pesar de las dificultades inherentes a estos procesos, es notorio que los cambios son posibles cuando hay mayor participación social, lo que permite comprometer a los gobiernos y a las instituciones en verdaderos cambios para lograr la búsqueda de la verdad, la justicia, la reparación y, sobre todo, para superar la exclusión y la impunidad.

En la realización del derecho a la verdad existen dos verdades: una factual y otra moral. La primera es la verdad que se logra en las narraciones de cómo ocurrió, y tratan de explicar por qué y a causa de quién (respecto de la verdad factual se puede decir que en Perú y en El Salvador esta verdad no se ha asumido oficialmente). Y la segunda verdad, la moral, requiere todo un proceso pedagógico para asumirla, por esta razón, la mayor parte de los gobiernos pierden interés en este proceso; solo en el caso argentino se logró algún resultado porque, paradójicamente, como durante muchos años, se vivió la falta de reconocimiento institucional, situación que generó una verdad moral institucional que en la práctica lo único que hizo fue prolongar los efectos del horror por el desaparecimiento forzado.

Es importante aclarar que la verdad factual no siempre lleva a la justicia. Y sin justicia, la verdad se niega fácilmente y se convierte en una versión más de los actores. La justicia es un requerimiento vital para hacer que los culpables reconozcan las acciones del pasado y restablezcan relaciones de equidad y respeto.

En los países latinoamericanos analizados se observa que estos procesos de búsqueda de la verdad han tenido una dimensión temporal más larga de la esperada, lo que ha hecho que no se pueda realizar el derecho a la justicia. El autor antes citado relata al respecto: 
En Chile, tan solo en el 2004, es decir, catorce años después de instaurada la CVR, se conoció el trabajo de investigación sobre prisión política y tortura, aunque solo cincuenta años después se podrán conocer los nombres de los responsables.

En Argentina la abolición de las leyes de Obediencia Debida y Punto Final se dio quince años después de que su aprobación cerrara el paso a la justicia. En el caso de Centroamérica, probablemente no se pueden sacar conclusiones a largo plazo respecto a cómo las políticas aplicadas sobre verdad y justicia han contribuido a sistemas más democráticos. Lo mismo sucede en Perú, donde el tiempo trascurrido desde la creación de la CVR es aún muy reciente. (IIDH, 2006b).

\section{Conclusiones y recomendaciones}

A manera de conclusión, las políticas de justicia transicional, verdad y reconciliación no tienen por sí solas la fuerza para democratizar un país, pero sí son instrumentos importantes para ello. Las iniciativas llevadas a cabo por organizaciones de familiares, afectados y grupos de derechos humanos han generado una mayor movilización social, negando la cultura del silencio y del miedo que ha contribuido a exigir sus derechos; pero también han acumulado frustración y desesperanza cuando no han tenido apoyo suficiente. Se infiere que los sistemas políticos de los países francófonos y algunos de América Latina, a pesar del componente electoral, siguen siendo impermeables a la voluntad de la población y a la ética de respeto a los derechos humanos.

Sin embargo, existe una esperanza con la justicia globalizada, y en especial con la justicia impartida por la Corte Penal Internacional, y para el caso de los países latinoamericanos, con aquella de la Corte Interamericana de Derechos Humanos. La historia reciente nos ha demostrado cómo la justicia internacional tiene efectos contra la desmemoria. Por ejemplo, los militares chilenos recuperaron la memoria cuando Pinochet estuvo detenido en Londres, y plantearon la posibilidad de entregar información a cambio de confidencialidad de las fuentes. Aunque estos militares hayan hecho todo lo posible por desaparecer los restos de los desaparecidos para ocultar las pruebas, de todos modos, se logró probar que el pacto de silencio entre los miembros de las fuerzas armadas solo podría quebrantarse si había presión de la justicia internacional.

En el caso del Perú, el reconocimiento de las violaciones de derechos humanos por parte de las fuerzas militares, a pesar de ser una práctica sistemática en 
determinados momentos del conflicto, se planteó inicialmente como excesos frente a la actuación del Sendero Luminoso. En los primeros casos que llevó la Comisión de la Verdad y la Reconciliación, el Estado se negó a facilitar la investigación tendiente a encontrar las fosas comunes, sin embargo, después de las presiones internacionales, se realizaron varias exhumaciones en algunos centros de detención, las cuales demostraron la responsabilidad del Estado.

En el Salvador, la amnistía bloqueó la justicia. El primer caso de El Salvador que llegó a la Corte Interamericana fue juzgado doce años después de la firma de la paz. La sentencia sobre la desaparición de las niñas Serrano Cruz condenó al Estado a investigar el destino de las desaparecidas, la reparación a los familiares y el reconocimiento público de los hechos por parte del Gobierno salvadoreño, abriendo así las puertas para las futuras investigaciones.

Los problemas y las revueltas sociales que ha tenido Bolivia, así como la grave crisis de legitimidad del Gobierno en este país, hacen pensar que todavía estamos lejos de un verdadero respeto a los derechos humanos. Si a esto le agregamos los fenómenos de polarización social vividos en Venezuela debemos suponer que aún no estamos cerca de una verdadera cultura democrática de realización y respeto de los derechos humanos.

Colombia, en medio del conflicto armado interno, sigue enfrentando los desafíos de la impunidad en el proceso de paz que hoy adelanta en Cuba con las FARC, con la necesaria perspectiva de buscar una salida negociada al conflicto.

Lo único cierto es que en este mundo globalizado, con una justicia internacional operando en todos los países miembros, el Estado colombiano debe responder por los actos y por las omisiones ante el derecho internacional de los derechos humanos, de ahí que la Oficina del Derecho del Alto Comisionado para las Naciones Unidas que opera en Colombia se encuentre verificando día a día si el Estado cumple con los derechos adquiridos ante la comunidad internacional, ejerciendo un control convencional difuso por medio de la jurisprudencia de la CIDH y los tratados de la ONU en torno al respeto por los derechos humanos en este territorio.

Si se logra continuar con el proceso de paz en el gobierno siguiente, su éxito dependerá de la satisfacción de la dimensión individual y colectiva del derecho a la verdad, la determinación judicial, la garantía de un proceso penal efectivo y adecuado, la investigación, el enjuiciamiento y la asignación de la responsabilidad penal a los responsables, lo que comprende tanto a los autores materiales e intelectuales como a quienes han contribuido de diferentes maneras al mantenimiento de las estructuras de poder de los grupos armados organizados al margen de la ley. 


\section{Referencias}

Andrieu, K. (2012). La justicia transicional. Francia: Editorial Gallimard.

Becerra, A. (septiembre de 2008). Seminario sobre la Ley de Justicia y Paz. Seminario realizado en la Universidad Santo Tomás, miembro de ILSA, actual miembro del Observatorio a la Verdad, la Justicia y la Reparación en Colombia. Universidad Santo Tomas, Bogotá.

Cancao, A. A. (2006). Responsabilidad, perdón y justicia como manifestación de la conciencia jurídica Universal. Revista Estudios Socio-Jurídicos, 8(1), 15-36.

Castellanos, E. N. (2005). Verdad, justicia y reparación en Argentina, El Salvador y Sudáfrica. Revista Estudios Sociojurídicos, 7(núm. Esp.), 200-249.

Cortes, S. (julio, 2016). Derechos humanos en las políticas de paz y posconflicto

en Colombia. Revista Via Inveniendi et Iudicandi, 11(1). Recuperado de http://revistas.usta. edu.co/index.php/viei/article/view/2926/2798

Huber, F. (2007). La Ley de Justicia y Paz, desafíos y temas de debate. Bogotá: Fescol.

Instituto Interamericano de Derechos Humanos. (2006a). Experiencia Latinoamérica: Encuentro de victimas por la esperanza. Bogotá: IIDH y Grupo Editorial Ibáñez.

Instituto Interamericano de Derechos Humanos. (2006b). Colombia ante la Corte Interamericana de Derechos Humanos (Colección Verdad, Justicia y Reparación). Bogotá: IIDH y Grupo Editorial Ibáñez.

Instituto Interamericano de Derechos Humanos. (2006). Conversatorio de actores sociales: Guatemala, El Salvador, Chile, Perú, Argentina (Colección Verdad, Justicia y Reparación). Bogotá: IIDH y Grupo Editorial Ibáñez.

Instituto Interamericano de Derechos Humanos. (2002) Desafios para la democracia y la convivencia social. (Colección Verdad, Justicia y Reparación). Bogotá: IIDH y Grupo Editorial Ibáñez.

Joinet, L. (2007). Un estado del arte de los principios y estándares internacionales de la justicia transicional. En La justicia transicional en el mundo francófono: estado del arte. conferencia de papel http://cnudhd.org/rapportjustice.pdf

Ley 1448 de 2001. Por la cual se dictan medidas de atención, asistencia y reparación integral a las víctimas del conflicto armado interno y se dictan otras disposiciones, Congreso de la República, Diario Oficial 48069 de junio 10 de 2011.

Londoño, V. y Hidven, S. (2007). Revisión bibliográfica sobre justicia transicional. Revista Estudios Socio-Jurídicos, 7(núm. Extra. 1), 547-591).

Organisation Internationale de la Francophonie. (2012) Rapport sur l'état des pratiques de la démocratie, des droits et des libertés dans l'espace francophone. Paris: OIF. Recuperado de http://goo.g1/IGMcoZ 
Organisation Internationale de la Francophonie. (2013). Guide practique. Les processus de transition, justice, vérité et réconciliation dans l'espace francophone. Paris: OIF. Recuperado de http://goo.gl/cFjYGN

Organisation Internationale de la Francophonie. (2014) Rapport sur l'état des pratiques de la démocratie, des droits et des libertés dans l'espace francophone. Paris: OIF. Recuperado de http://goo.g1/q2Cm8Q

Ríos González, G. (2001). Guerra y paz, los rostros del conflicto. Bogotá: Fundación Centro Andino de Estudios.

Vicepresidencia de la República de Colombia, Programa Presidencial de Derechos Humanos. (2002). Verdad, justicia y reparación. Corte Penal Internacional. Bogotá: Programa USAID MSD.

Villarraga Sarmiento, Á. (2003). Educación para la paz: acuerdos humanitarios, diagnóstico en derechos humanos y DIH, agendas de paz y mecanismos de resistencia civil. Medellín: Instituto Popular de Capacitación (IPC). 